\title{
A compreensão da argumentação linguística: hipótese de interação entre leitura e oralidade ${ }^{1}$
}

\section{Linguistic argumentation comprehension: reading and oral language interaction hypothesis}

\author{
Ana Cláudia de Souza \\ UFSC \\ anacs3@gmail.com \\ Helena Cristina Weirich \\ UFSC \\ helenaweirich@gmail.com \\ Leonilda Procailo \\ Unicentro/UFSC \\ lprocailo@gmail.com
}

Resumo: Este artigo objetiva desenvolver e discutir aspectos teóricos relativos à hipótese que fundamenta a interação entre os sistemas linguísticos verbais, no que diz respeito à interferência do conhecimento da linguagem verbal escrita para fins de leitura na maneira como se compreendem aspectos da argumentação linguística na oralidade. A hipótese discutida se fundamenta nos estudos de Olson (1977; 1996; 1997), e a perspectiva de argumentação linguística, nas formulações teóricas de Ducrot $(1987 ; 1989 ; 2002)$. Se o domínio da leitura interfere no modo de compreensão de articuladores de argumentação linguística, é possível que se explique por que tais elementos da linguagem verbal, conforme advoga Kail $(1978 ; 2013)$, são adquiridos tardiamente.

\footnotetext{
${ }^{1}$ Agradecemos ao CNPq e à SETI/FUNDAÇÃO ARAUCÁRIA/CAPES, pelo apoio aos estudos de pós-graduação da segunda e da terceira autora, respectivamente.
} 
Palavras-chave: compreensão da linguagem; argumentação linguística; domínio da leitura; hipótese da interação entre os domínios linguísticos escrito e oral.

Abstract: The present article aims at developing and discussing theoretical aspects pertaining to the hypothesis that underlies the interaction between verbal linguistic systems in terms of interference of written verbal language knowledge with reading purposes in the way comprehension aspects of oral linguistic argumentation happen. The hypothesis under discussion herein is grounded in studies by Olson $(1977 ; 1996 ; 1997)$, and the linguistic argumentation perspective is based on the theoretical formulations by Ducrot (1987; 1989; 2002). If reading ability influences the way connectives of linguistic argumentation are comprehended, it is plausible to argue that those verbal language elements, according to Kail (1978; 2013), are only acquired later.

Keywords: language comprehension; linguistic argumentation; reading ability; oral and written linguistic domains interaction hypothesis.

Recebido em: 31 de maio de 2016.

Aprovado em: 25 de julho de 2016.

\section{Introdução}

Diferentemente da fala, que se caracteriza por ser uma propriedade biologicamente humana, os sistemas de escrita são fruto de invenção e dependem de aprendizagem para serem conhecidos, não estando disponíveis ao acesso apenas por imersão do sujeito em ambientes nos quais seu uso e circulação ocorrem. As escritas foram criadas por meio de tecnologias, a fim de registrar as informações e de promover a comunicação e a interação sem a presença concomitante dos sujeitos (OLSON, 1996), tendo-se desenvolvido, no que diz respeito à escrita alfabética, na direção do registro de informações linguísticas orais e, portanto, acústicas, em forma gráfica - por meio de letras - e, assim, visual (SCLIAR-CABRAL, 2003; SOUZA, 2012; FROST, 2013).

Dadas as diferentes características das realizações linguísticas verbal oral e escrita, os processos de aproximação a elas e de apropriação delas também se distinguem. Enquanto a oralidade é tipicamente 
adquirida, precoce e espontaneamente, logo nos primeiros anos de vida, em contextos de uso e interação social, a escrita implica a implementação de processos de ensino, normalmente escolares, e é aprendida tardiamente em comparação à aquisição da oralidade, exigindo, inclusive, domínio linguístico suficiente para realizar operações metalinguísticas específicas de natureza fonológica, ortográfica, morfológica, sintática e semântica.

Segundo Olson e Oatley (2014), a escrita é tanto uma tecnologia de comunicação quanto um instrumento de pensamento. Nesta perspectiva, oralidade e escrita não se distinguem somente pelo fato de esta ser uma tecnologia de representação visual daquela, mas uma tecnologia que permite conceitualizar a língua, tomando-a de modo desconectado ou, como nomeiam os autores, "off-line". Isso significa dizer que, por meio da escrita, a língua é tomada e pensada entre aspas, ou seja, a escrita promove um desligamento da condição e da situação da produção linguística (do falante, do tempo, do espaço), do contexto de expressão e das intenções do autor.

A relevância do acesso a um sistema de escrita nos e para os processos escolarizados e para a inserção e interação social dos sujeitos tem sido considerada, descrita e discutida em muitos estudos que se voltam tanto às práticas e às políticas educacionais, quanto aos aspectos linguísticos, culturais, sociais e históricos da constituição dos sujeitos e dos grupos sociais (CAGLIARI, 1998; CASTRO, 1999; KAMIL; MOSENTHAL; PEARSON; BARR, 2000; ABREU, 2000; CHARTIER, 1996; 2002; BRITTO, 2012; MORAIS, 2014). É consensual que saber ler e escrever abre possibilidades de circulação e deslocamento ao sujeito e de acesso a informações que não são veiculadas senão por meio de um sistema de escrita. O que não parece ser consensual é o fato de a escrita, segundo argumenta Olson em seus estudos, ser o meio que permite refletir sobre a língua, transformando-a em objeto de análise e, assim, modificando a relação dos sujeitos com a própria língua e com a oralidade.

Quando se trata de sistemas de escrita que se organizam a partir de unidades linguísticas básicas abstratas constitutivas da oralidade, a exemplo dos sistemas alfabéticos aos quais nos referimos neste artigo, tem-se advogado que a imersão, a aprendizagem e o uso efetivo da escrita para fins de leitura se relacionam aos conhecimentos linguísticos prévios de que os indivíduos já dispõem, quando se deparam com a 
escrita $^{2}$ e iniciam os procedimentos e processos básicos para decifrá-la. Tais conhecimentos são relativos à língua, ao sistema linguístico, cuja natureza é verbal oral.

Neste artigo, assume-se que os sistemas alfabéticos de escrita, ainda que guardem memória etimológica (não há exatamente nada em língua, se não há memória, memória coletiva e do próprio sistema, e memória individual, do sujeito da linguagem), se constituem a partir de uma base de natureza fonológica, o que significa dizer, especificamente, que, em um sistema alfabético, a palavra é representada por meio da conversão dos fonemas em grafemas, na escrita ${ }^{3}$. Assim, os grafemas, que se concretizam por meio dos símbolos aos quais damos o nome de letra, representam os fonemas da língua que notam ou registram (SCLIARCABRAL, 2003; GODOY, 2005; FARACO, 2012; SOUZA, 2012).

Daí é possível justificar tantas pesquisas que se voltam à investigação do papel que a representação e o processamento fonológico têm no aprendizado inicial de sistemas de escrita alfabéticos (McGUINNESS, 1999, 2006; BLACHMAN, 2000; SCLIAR-CABRAL, 2003, 2013; MORAIS, 2012; LEYBAERT, 2013; EHRI, 2013; ORDEN; KLOOS, 2013; GODOY, 2005; SALLES; PARENTE, 2002, entre muitos outros). Uma das questões em debate diz respeito a ela ser preditiva da aprendizagem, dela decorrente ou seu desenvolvimento ocorrer à medida em que há imersão no sistema de escrita.

Se o papel do conhecimento linguístico oral tem sido investigado na aprendizagem da leitura (inclusive nos casos em que os sujeitos têm

\footnotetext{
${ }^{2}$ Referimo-nos, neste artigo, à escrita sempre como sistema, não como atividade ou ato de escrever.

${ }^{3}$ Cagliari (1998) assume perspectiva distinta, defendendo que as letras representam unidades fonéticas não correspondentes aos fonemas. Tal perspectiva parece encontrar evidência apenas no que diz respeito à relação do sujeito com a escrita, quando da conversão para seu próprio dialeto. Entretanto, no que concerne ao sistema de escrita, não parece haver respaldo para a possibilidade de uma escrita de bases fonéticas (MORAIS, 2011; SCLIAR-CABRAL, 2003). Ademais, há que se considerar as evidências que vêm sendo apresentadas por estudos que investigam a relação entre leitura/escrita e consciência fonológica, nos quais se discute o papel desta consciência no desenvolvimento da leitura e/ou da escrita, não parecendo haver leitores que não a tenham desenvolvido, principalmente em relação à consciência fonêmica (LEYBAERT, 2013; SCLIAR, 2013; MORAIS, 2012; GODOY, 2005; SALLES; PARENTE, 2002; McGUINNESS, 2006).
} 
restrição de acesso ao sinal acústico, como na surdez (LEYBAERT, 2013; SEIMETZ-RODRIGUES; SOUZA, 2016), o mesmo não se pode dizer do papel que a aprendizagem da escrita, por meio do domínio dos processos de leitura, teria nos usos linguísticos orais no que diz respeito à compreensão.

Segundo o que sintetiza Kail (2013), com base em suas próprias pesquisas (KAIL, 1978; KAIL; WEISSENBORN, 1984; 1991) e em estudos desenvolvidos por Anscombre e Ducrot (1977), no processo de aquisição da linguagem oral, a compreensão de conteúdos não explícitos ocorre tardiamente, ou seja, somente depois dos 7 anos de idade 4 . Até essa fase, de acordo com a perspectiva assumida pela autora a qual dá respaldo à hipótese aqui discutida, a criança parece acessar apenas o conteúdo linguístico manifestado explicitamente, não tendo sensibilidade para perceber elementos linguísticos indicativos da relação entre os conteúdos expressos por meio da língua. Com isso, a autora não defende a existência de uma idade mágica. O que ela discute é que a relação do sujeito com a linguagem verbal oral vai aumentando em complexidade e em condição analítica à medida que aumentam as experiências linguísticas dos sujeitos.

Nesse sentido, a criança julgaria como aceitável um enunciado do tipo "Você brincou a tarde inteira na rua, mas está sujo e suado", por não perceber ou não se ter apropriado do valor do mas no estabelecimento da relação entre as orações que constituem o enunciado. Assim, entendendo que brincar na rua faz suar e ficar com o corpo sujo, ela aceita o enunciado e talvez até argumente com a mãe a respeito dele dizendo algo como "Eu estava fazendo buraco no quintal", não notando que o mas anuncia uma quebra de expectativa ou, conforme Ducrot e Carel (2008), um encadeamento argumentativo transgressivo. A argumentação que a criança elaboraria nesta fase não parece estar respaldada na análise da organização linguística do enunciado, já que, se assim o fosse, a criança perceberia um encadeamento inaceitável no enunciado materno.

\footnotetext{
${ }^{4}$ Em relação à aquisição de conteúdos implícitos, há uma perspectiva distinta da assumida neste artigo, segundo a qual a criança interage socialmente de modo significativo, desde a tenra idade, demonstrando compreender conteúdos implícitos e sendo capaz de produzir marcas de argumentação e, também, de humor. Tais pesquisas buscam respaldo em orientações teóricas que se pautam no diálogo como unidade de análise (LEMOS, 2012; DEL RÉ, 2003, 2013; CASTRO, 1992; VIEIRA; LEITÃO, 2014).
} 
Considerando a exposição de Kail (2013), a argumentação linguística conforme descrita por Ducrot $(1987 ; 1989 ; 2002 ; 2009)$ e Anscombre e Ducrot (1977), e a perspectiva, segundo Olson (1977), da interação entre os sistemas linguísticos escrito e oral no processamento e na compreensão da linguagem, o que faz com que a escrita se constitua como um modelo para a oralidade, nesta pesquisa, busca-se respaldo teórico à hipótese de que a aquisição tardia de elementos linguísticos cuja compreensão e cujo uso exigem acesso ao conteúdo implícito está vinculada ao período inicial do ensino fundamental, no qual a criança é convidada a refletir sobre a linguagem e a imergir no sistema de escrita por meio do processo de alfabetização. Como desdobramento dessa hipótese, explora-se teoricamente, ainda, a possibilidade de o envolvimento do sujeito em contextos nos quais a metalinguagem seja requerida, independentemente da faixa etária, e nos quais se instancia o erro, promover a reflexão sobre as diferenças de valores e funções de tais elementos linguísticos de encadeamento argumentativo cuja compreensão exige o acesso ao conteúdo partilhado, mas não manifestado.

Experiências pedagógicas com a educação de jovens e adultos ainda não plenamente alfabetizados ${ }^{5}$ ou alfabetizados apenas em termos rudimentares parecem dar sustentação às hipóteses acima levantadas, uma vez que sujeitos, mesmo em idade adulta, sem que estejam plenamente alfabetizados, cometem falhas recorrentes de compreensão e uso de tais elementos que desempenham papel linguístico no encadeamento entre as orações sendo indicativos de transgressão argumentativa (WEIRICH, 2016).

Quanto ao método de pesquisa empregado no desenvolvimento do estudo teórico aqui descrito, seguimos o que recomendam autores como Vasconcelos (2013), Gray (2012) e Gil (2010) sobre a pesquisa bibliográfica e sua jornada. Assim, depois de termos recorrido aos fundamentos acerca da teoria da argumentação na língua e das relações entre a fala e a escrita no processamento e na compreensão da linguagem, entre em agosto e setembro de 2015 e novamente entre março e abril

\footnotetext{
${ }^{5} \mathrm{O}$ termo plenamente alfabetizado se refere a indivíduos que, além de usarem produtivamente o sistema de escrita, nos processos de decodificação e codificação com vistas à significação, produzem sentidos a partir daquilo que leem e escrevem, mesmo que esses sentidos se restrinjam à micro e à macroestrutura textual (sem a construção de um modelo situacional).
} 
de 2016, procedemos a buscas de publicações no banco de teses e dissertações e no portal de periódicos da Capes, usando como critério a busca avançada por assunto, com os termos, em português e inglês, sem restrição à data de publicação: (1) aquisição de linguagem, ou aprendizagem da escrita, ou aprendizagem da leitura, ou aquisição da escrita, ou aquisição da leitura; e (2) conectivos, ou conjunções, ou conectores lógicos, ou elementos coesivos, ou articulares argumentativos, ou encadeadores argumentativos ou mas.

\section{A argumentação linguística}

A teoria da argumentação na língua, também nomeada como semântica argumentativa, foi fundada na École des Hautes Études em Sciences de Paris, tendo como principal nome Oswald Ducrot que, inicialmente, atuou em coautoria com Jean-Claude Anscombre e, atualmente, trabalha com Marion Carel, com quem tem desenvolvido a teoria dos blocos semânticos. Na presente pesquisa, o que abordamos da teoria da argumentação na língua não pretende explicá-la em seus pormenores, tampouco abordá-la em todos os seus minuciosos aprimoramentos. Optamos por apresentar sinteticamente este aparato teórico, porque a hipótese aqui discutida repousa sobre processamento linguístico (não discursivo). Especificamente, processamento e compreensão de articuladores argumentativos, que, segundo defende Kail (1978; 2013), são adquiridos tardiamente. Tal aquisição tardia parece ocorrer em momento no qual os indivíduos já entraram em contato efetivo e significativo com o sistema de escrita, que passa a fazer parte dos usos linguísticos cotidianos deles e, por hipótese, interferir nos conceitos e usos da língua como um todo.

O ponto de partida dessa teoria é definido pelo próprio slogan, formulado por Ducrot e Anscombre e que dá nome à teoria "A argumentação está na língua" (DUCROT, 1989). Essa premissa sintetiza a ideia geral e, em função dela, a teoria passou por três fases, facilmente identificáveis (forma padrão, topoi e blocos semânticos), nas quais a ideia de argumentação sofreu alterações, mas não a essência da teoria. A busca dos teóricos tem sido a de tirar da teoria tudo aquilo que possa ser identificado como externo à língua, ou seja, eles têm visado demonstrar que há um tipo de argumentação que se insere na língua, e 
o extralinguístico (o que inclui o discursivo) não precisa ser evocado para explicá-lo.

Em uma primeira fase, conhecida como forma padrão da teoria, Ducrot lança a base de sua hipótese, enfatizando que a argumentação na língua não pode ser confundida com a concepção tradicional de argumentação, a retórica. A argumentação retórica daria conta dos casos em que o falante produz determinado argumento (A) para justificar outro enunciado (C) (DUCROT, 1989). Segundo o autor, esse tipo de enunciado, em português, ganha a forma "A logo C" ou "C já que A". A ideia por trás da argumentação retórica é a de que o enunciado A representa uma realidade, a qual pode ser tida como verdadeira ou falsa. O falante deve, então, supor que o próprio fato $(\mathrm{F})$ leva à conclusão $\mathrm{C}$.

A partir disso, o autor afirma que, neste tipo de argumentação, não é a língua que tem papel essencial, mas o discurso. O papel da língua é oferecer conectivos que marcam uma relação argumentativa existente entre $\mathrm{A}$ e $\mathrm{C}$, propiciando a estrutura, que é linguística, (A) que aponta para um fato (F). Segundo o autor, o movimento argumentativo que conduz à determinada conclusão é independente da língua e é explicado pela situação discursiva e por princípios lógicos, psicológicos, retóricos ou sociológicos (DUCROT, 1989; para uma revisão acerca do que constitui a argumentação retórica e a argumentação linguística, ver DUCROT, 2009).

O tipo de argumentação com o qual Ducrot opera em sua teoria é aquele inerente à língua, buscando explicar o "movimento argumentativo" a partir de mecanismos e princípios linguísticos. Na fase inicial, Ducrot considerava que a força argumentativa de um dado enunciado (A) poderia ser definida por um conjunto de enunciados que surgiriam como conclusão de A. Neste contexto, o autor explicava a diferença entre enunciados como "Maria comeu pouco ontem" e "Maria comeu um pouco ontem", os quais representam o mesmo fato da realidade, mas não permitem movimentos argumentativos idênticos, por meio de um conjunto de conclusões gerados pelos operadores argumentativos pouco e um pouсо. Ducrot (2009) propõe que a diferença entre os dois operadores se encontra nos encadeamentos possíveis a partir deles, como em "João treinou um pouco, portanto vai vencer" e "João treinou pouco, portanto vai perder". Assim, a partir da significação de pouco e um pouco há a indicação antecipada do que pode ser concluído. Neste período da teoria, 
a argumentatividade de um enunciado era, portanto, caracterizada pelo conjunto de conclusões possíveis.

Ducrot, todavia, concluiu que "as possibilidades de argumentação não dependem somente dos enunciados tomados por argumentos e conclusões, mas também dos princípios dos quais se serve para colocálos em relação" (DUCROT, 1989, p.21). Assim, entra em cena a segunda forma da teoria da argumentação na língua, os topoi argumentativos, na qual o autor apresenta uma descrição dos enunciados com o mas, defendendo que a orientação argumentativa de dado elemento semântico de um enunciado (e), orientada para uma determinada conclusão (r), é baseada em um princípio linguístico argumentativo, nomeado como topos, que possui três propriedades: universalidade, generalidade e gradação. A universalidade remete ao fato de que o topos é comum ou aceito por uma coletividade ou, pelos menos, assimilável pelo locutor e pelo alocutário. A generalidade trata da possibilidade de generalização do emprego do mesmo topos. A terceira propriedade, gradação, sustenta que a passagem do enunciado para a conclusão é gradual. Isso significa que os topoi põem em relação duas escalas, na condição em que mudança ou movimento em qualquer uma delas provoca mudança ou movimento na outra, constituindo, os próprios topoi, relações complexas. Como exemplo, em "Sou rico, estou feliz", no qual o topos utilizado é a riqueza traz felicidade, não apenas se relacionam as escalas da riqueza e de felicidade, mas se "constitui a noção de uma felicidade obtida a partir da riqueza e de uma riqueza suscetível de trazer felicidade" (MOURA, 1998, p. 4).

É importante destacar que, para Ducrot (1987), a enunciação é constitutiva do sentido dos enunciados de uma língua. É a atividade linguística que integra os enunciados na cena discursiva. Assim, do ponto de vista deste teórico, no mínimo, deve-se aludir à enunciação para a descrição semântica possível e completa de uma língua.

No contexto da teoria dos topoi, em relação ao mas, Ducrot analisa o seguinte exemplo: "É verdade, está quente, mas não o suficiente" (1989, p.31), explicando que, com o emprego do mas, o enunciador "não somente admite o fato de que está quente, mas que ele admite também o valor argumentativo deste fato, ou seja, a validade do topos. No entanto, acrescentando não o suficiente, ele se recusa, na situação presente, a utilizar esse topos, que ele utilizaria somente se o calor fosse maior" (1989, p.31). Ademais, ele defende que, em uma sequência "p 
mas q", está implicado que p veicula um conteúdo dirigido para uma dada conclusão, que q está dirigido para uma conclusão contrária e que a conclusão veiculada pelo discurso é feita a partir de q, não de $\mathrm{p}$.

Vogt (1974) discute, baseado na descrição semântica proposta por Ducrot (1973) o papel do mas, opondo-se à noção de que $p$ mas $q$ seja decomposto em três elementos, a saber: $-p$, $-q$, -oposição entre $p$ e $q$. Segundo o autor, essa decomposição que coloca $q$ em oposição a $p$ poderia ser aplicada a diversos enunciados, no entanto, centenas de outros estariam excluídos. Como ilustração, Vogt analisa o enunciado "Maria foi ao baile mas estava com a mãe" (p. 27) e demonstra que não há oposição entre as duas proposições ligadas pela conjunção mas dada a seguinte situação de discurso entre $A$ e $B: A$-interessado em Maria; $B$ - confidente de $A$; Mãe de Maria: contrária à relação (situação conhecida de ambos). Dada essa situação, a proposição $q$ (Maria estava com a mãe) introduzida por mas não é elemento que opõe $p$ a $q$, mas o elemento que tira de $B$ a conclusão $r$ sugerida pela proposição $p$ (Maria foi ao baile, então vocês ficaram juntos). Assim, o valor do significado depende de fatores como ato de enunciação ou situação de discurso.

Ducrot, em seu livro Polifonía y Argumentación (1988 apud WELP, 2005) elabora uma descrição analítica dos enunciados que apresentam o mas, que foi, depois, nomeado como articulador (DUCROT, 2002), explicando que construções com o mas argumentativo acionam a voz de quatro enunciadores, isto é, de quatro distintas origens que caracterizam cada ponto de vista expresso. Assim a significação de frases com mas se dá pelo seguinte conjunto de instruções que cada enunciador oferece ao interlocutor em enunciados do tipo "X mas $Y$ ": 1) Construa quatro enunciadores. $O$ enunciador $E 1$ contém o ponto de vista $\mathrm{X}$. $\mathrm{O}$ enunciador $\mathrm{E} 2$ tira uma conclusão $\mathrm{r}$ de $\mathrm{X}$. $\mathrm{O}$ enunciador E3 sustenta o ponto de vista Y. A partir de Y, o E4 conclui não r; 2) Busque os posicionamentos do locutor em relação aos enunciadores. Vejamos um exemplo, que segundo Welp (2005, p. 306), manifesta a gestação da ideia do articulador mas relacionando dois blocos semânticos: "Sim, faz bom tempo, mas me doem os pés." Neste caso, em que há a recusa a um convite, há quatro enunciadores $(\mathrm{E})$, pelo menos, que devem ser identificados pelo interlocutor: E1, que afirma que faz bom tempo; E2, que fundamenta o convite com base no bom tempo; E3, que manifesta a dor nos pés do locutor; e E4, que conclui, com base na dor nos pés do locutor, que o passeio não vai acontecer (recusa ao convite). Observando 
a segunda instrução, o interlocutor deve localizar os enunciadores com os quais o locutor se identifica. Neste caso, o locutor recusa E2 e se identifica com E4, por meio do emprego do articulador mas. Em relação à E1 e E3, não há recusa.

No caso do mas como elemento opositor, a função dele é a de introduzir uma nova proposição, que orienta para a conclusão não-r. Assim, temos, por exemplo, "Ele joga pouco, mas foi mantido no time titular", em que a primeira oração (p), "ele joga pouco", orienta para a conclusão (r), "quem joga pouco é excluído do time titular". No entanto, o mas permite articular a oração (q), "foi mantido no time", a qual leva à conclusão não-r, ou seja, a conclusão suscitada por (p) não é válida para o locutor. Neste tipo de uso do mas, o argumento inicial continua sendo legítimo; no entanto, há um argumento que se opõe a isso e é mais forte.

Discutiremos aqui, brevemente, as relações estabelecidas pelo mas a partir da classificação que Ducrot e Carel (2008) atribuem ao seu equivalente no entanto na discussão do que chamam de "encadeamentos argumentativos". Os autores definem argumentação como dois enunciados em sequência ligados por um conector. Porém, nessa definição, segundo os autores, há que se atentar para a não rigidez dos enunciados. Assim, em "o caminhão está carregado, mas se move rapidamente", "está carregado" é suporte tanto em "está carregado, no entanto se move rapidamente" quanto em "se move rapidamente mesmo carregado". Esse encadeamento argumentativo é classificado por Ducrot e Carel como "transgressivo" em oposição ao encadeamento "normativo". Essa classificação está fundamentada na Teoria de Blocos Semânticos de Carel (1995), segundo a qual os segmentos que constituem um encadeamento argumentativo são dependentes semanticamente, ou seja, podem ser unidos por um conector donc (portanto) ou por um conector pourtant (no entanto). Como ilustração, os enunciados "o atleta está cansado, portanto desistiu da prova" (aspecto normativo) e "o atleta está cansado, mas não desistiu da prova" (aspecto transgressivo) podem ser entendidos como equivalentes por compartilharem do mesmo princípio: desistir da prova. Dessa maneira, tanto o encadeador normativo quanto o transgressivo partilham do mesmo bloco semântico.

Ainda que o mas possa assumir diversas funções na língua, aquela que aqui nos cabe discutir diz respeito apenas a ele como articulador linguístico argumentativo. Nesse sentido, o mas articula vozes de enunciadores que se opõem, exercendo o papel de relacionar 
os pontos de vista, de maneira a negar a conclusão da primeira oração, sem recusar o ponto de vista do primeiro enunciador. Ademais, o que é fundamental à pesquisa aqui apresentada, Ducrot insere este elemento em uma visão específica de língua, tomada como interna e inerentemente argumentativa, o que permite compreender que a própria língua propicia determinados encadeamentos e não outros, segundo os topoi convocados para sua interpretação.

\section{A interação entre a oralidade e a leitura: processamento e compreensão da linguagem verbal}

Nesta seção, será apresentada a hipótese de Olson (1977; 1996; 1997) acerca do papel do conhecimento do sistema de escrita, principalmente da leitura, nas conceitualizações, reflexões e usos da linguagem verbal, que deu origem à hipótese aqui discutida sobre as possíveis mudanças na maneira como a linguagem verbal oral pode ser percebida e compreendida, naquilo que diz respeito a aspectos ou unidades da argumentação linguística, à luz do domínio do sistema de escrita por meio da leitura. A perspectiva teórica de Olson procura relacionar, desde sua proposição em 1977, mente e escrita, e fundamenta a ideia de que os sistemas de escrita provocam alterações culturais e cognitivas. Para este pesquisador, a leitura se constitui como um modelo para a oralidade, permitindo seu processamento, entendimento e análise de modo específico e diferenciado, o que não significa dizer que quem não lê não compreende ou não analisa a linguagem. Significa, sim, assumir que saber ler altera os modos de relação com e de compreensão da linguagem verbal e possibilita a contemplação e a retomada da própria estrutura linguística para além do seu uso.

Segundo Olson e Oatley (2014, p. 31), a escrita tem vantagem sobre a fala, em razão de um par de fatores que quem aprende a ler passa a entender e gerenciar. O primeiro deles diz respeito ao fato de que a escrita fornece um artefato visível e resistente à passagem do tempo e à mudança no espaço. O segundo se refere à possibilidade de este artefato representar e tornar disponíveis para análise aspectos da forma linguística que, quando trazidos à consciência pela desautomatização do uso, podem ser explorados com objetivos específicos que ultrapassam a mensagem ou a interação por meio da linguagem. Tais aspectos da forma podem se tornar conscientes por meio da aprendizagem de um conjunto de 
conceitos metalinguísticos e de normas interpretativas que explicitam as propriedades outrora implícitas da linguagem. Essa reflexividade, para os autores, é a rota para a tomada de consciência de aspectos da forma e do sentido linguísticos.

Ainda que pesquisas com um ponto de vista radical sobre a hipótese das implicações da escrita nos modos de organização do pensamento, da linguagem e da cultura (literacy hypothesis) tenham sido criticadas nos anos 80, Olson modalizou essa premissa, permitindo a compreensão sobre o modo como a leitura pode atuar sobre habilidades linguísticas e cognitivas. De acordo com o autor, a invenção da escrita foi capaz de trazer à consciência aspectos da linguagem falada, tornandoos objetos de reflexão, análise e planejamento (OLSON, 1997, p. 274). Desse modo, não parece ser necessário pensar que os inventores dos sistemas de escrita possuíssem um conhecimento metalinguístico prévio. Ao contrário, os sistemas de escrita, elaborados inicialmente apenas para transmitir informações, tornaram-se modelos para a reflexão e análise da oralidade. Ainda que nenhum modelo de escrita evidencie todos os aspectos do que é dito, aquilo que é representado pode ser trazido à consciência (OLSON, 1997, p. 276-276). Dessa maneira, uma vez que o modelo tenha sido assimilado, "é extremamente difícil não pensar nesse modelo e observar como uma pessoa não familiarizada com ele perceberia a linguagem" (OLSON, 1997, p.278).

De acordo com Olson, a leitura propicia um modelo por meio do qual somos capazes de categorizar e refletir sobre a linguagem verbal oral. Dessa maneira, aprender a ler é, basicamente, "encontrar ou detectar aspectos da estrutura linguística implícita própria de alguém que possa ser mapeada ou representada por elementos de tal roteiro. Consequentemente, uma vez leitoras, as pessoas tendem a ouvir sua fala de acordo com o modelo fornecido pelo impresso" (OLSON, 1996, p. 93, tradução nossa ${ }^{6}$ ).

É importante salientar que Olson argumenta que não é a atividade da escrita que implica alterações, mas a da leitura, enquanto competência para explorar aspectos culturais específicos. Como sugere o próprio autor (1997, p.35):

\footnotetext{
${ }^{6}$ Excerto original: [...] "to find or detect aspects of one's own implicit linguistic structure that can map onto or be represented by elements of that script. Consequently, once they are readers, people tend to hear their speech in terms of the model provided by print" (OLSON, 1996, p. 93).
} 


\begin{abstract}
é a arte da leitura que permite que um texto seja adotado como modelo para a forma verbal, ou seja, para 'o que é dito'. Esses modelos do que é dito - sejam eles sons, palavras ou frases - são sempre incompletos, ocasionando problemas de interpretação. Enquanto a escrita fornece modelos razoavelmente adequados para o que é dito, seus modelos para a interpretação do que é dito (em termos modernos, sua força ilocucionária) são menos adequados.
\end{abstract}

Olson, de maneira geral, sugere que a leitura propicia um modelo para a compreensão de unidades linguísticas que são representadas na escrita. Conforme revisão de Morais e Kolinsky (2013), essa hipótese teórica tem respaldo empírico somente no que se refere às habilidades metafônicas, já que a maioria das pesquisas sobre os efeitos do letramento tomam por base a consciência da estrutura sonora das palavras. Destacase que estes autores, no texto de 2013, tratam da relação entre letramento e mudança cognitiva e assumem que "o letramento é o conjunto de representações e processos que o indivíduo adquire como consequência obrigatória e direta de aprender a ler e escrever" (2013, p. 207).

Para Olson (1997), os povos falantes de línguas ágrafas (o que se poderia estender para sujeitos falantes, não leitores, de línguas que possuem representação escrita), também têm percepção da linguagem e também operam metalinguisticamente, fato que se pode observar nas onomatopeias, trocadilhos, repentes, rimas, poesias, generalizações de regras e nos recursos para lembrar ou contar o que foi dito e como deve ser entendido e também para inventar histórias ficcionais. Os recursos mnemônicos relativos à linguagem também são observados na ausência da escrita como sistema. Todavia, tanto as questões metalinguísticas quanto as mnemônicas são distintas diante da existência, do contato e do domínio da escrita, por meio da competência e da experiência em leitura. A memorização ipisis verbis, por exemplo, parece ser um traço específico propiciado pela escrita, por depender do confronto entre o que se armazena na memória e o documento original. Tal possibilidade de ampliação da memória potencializada pela escrita também é assumida por Faraco (2012).

Mesmo diante da hipótese de que a escrita produz mudanças na relação dos sujeitos com a linguagem verbal, no que diz respeito ao processamento e à compreensão e também no que concerne à conceitualização, é fundamental enfatizar que indivíduos iletrados 
e sociedades ou grupos ágrafos não são nem linguística nem cognitivamente comprometidos ou debilitados. E, para além disso, enquanto a aprendizagem da leitura em uma sociedade tradicionalmente escrita tem evidente utilidade e efeito, isso não parece se confirmar nos efeitos sociais e psicológicos previstos pela hipótese do letramento (OLSON; OATLEY, 2014).

Na perspectiva de Olson, a criação dos sistemas de escrita em parte representou a descoberta de algo a mais sobre a fala, e a aprendizagem da leitura é, de modo semelhante, a descoberta de algo a mais sobre como nossa fala pode ser compreendida (e até mal compreendida), coisa que, sem a presença da escrita, não parece se tornar real para a criança, o que não significa dizer que a criança, antes de estar plenamente alfabetizada, não reflita sobre a linguagem verbal e não tenha consciência dela. Significa tão-somente que acessar um sistema de escrita, por meio dos processos de leitura, permite ao sujeito uma análise específica da língua em seus pormenores linguísticos a respeito de elementos que possivelmente façam parte do uso da linguagem, mas ainda não estejam disponíveis ao pensamento. Assim, o pesquisador assevera que o texto escrito fornece um modelo para a fala e, parafraseando Benjamin Whorf, afirma que "introspectamos nossa língua por meio das linhas estabelecidas pelos nossos roteiros"7 (OLSON, 1996, p.100, tradução nossa). Essa perspectiva produz uma análise bem diferente das implicações conceituais da escrita, respondendo em grande parte por trazer a linguagem ao nível da consciência.

A teorização de Olson é fundamentada e desenvolvida a partir de oito princípios, conforme descrito em sua obra publicada em português em 1997 (p. 274-286), quais sejam: 1) É a escrita que possibilita a tomada de consciência de certos aspectos da linguagem falada, ou seja, é ela que os torna objeto de reflexão, análise e planejamento; 2) Não há sistema de escrita, incluindo o alfabético, que represente e torne evidente todos os aspectos do que é dito; 3) O que não é representado pela escrita como modelo é difícil ou talvez impossível tornar consciente; 4) Uma vez que uma escrita-como-modelo é assimilada, é extremamente complicado não pensar nesse modelo e observar como uma pessoa não familiarizada com ele perceberia a linguagem verbal; 5) As capacidades expressivas e

${ }^{7}$ Excerto original: $[. .$.$] "we introspect our language along lines laid down by our scripts"$ (OLSON, 1996, p.100). 
reflexivas da fala e da escrita são complementares, não similares. Assim, a aprendizagem da leitura significa a aprendizagem acerca de como lidar, dispondo somente do texto, com o que não é expresso linguisticamente; 6) Uma consequência importante provocada pelo uso da escrita deriva da tentativa de compensar o que se perdeu no ato de transcrição e seleção do que representar; 7) Sempre que os textos são lidos de uma nova maneira, a natureza é "lida" de modo analogamente novo; 8) Tão logo se reconheça a força ilocucionária de um texto como expressão de uma intencionalidade pessoal e privada, os conceitos que representam o modo como um texto deve ser interpretado fornecem exatamente os conceitos necessários para a representação da mente.

À luz do que propõe Olson, não é propriamente a escrita que gera nova maneira de pensar e sim os usos que se fazem dela, a partir das possibilidades de planejamento, reavaliação, estudo e interpretação de um dado texto, tomado distante de suas condições de produção. Somente a escrita, como sistema, parece possibilitar a preservação daquilo que foi realmente dito, não das intenções, para ser comparado com posteriores interpretações. Assim, a escrita possibilitaria refletir e tomar consciência da língua.

\section{O saber ler e a aquisição de conectivos: estudos com enfoque na aquisição tardia de conectivos e sua relação com o acesso e o uso do sistema de escrita}

O perfil de aquisição da argumentação é um tema em que há divergência entre os estudiosos, o que se deve, entre outras coisas, à abordagem teórica do objeto "argumentação", bem como às diferentes metodologias empregadas (o que, também, é decorrente de abordagem teórica). Leitão e Banks-Leite (2013), apresentam duas principais correntes. Enquanto os estudos baseados na tradição filosófico-retórica apontam para um perfil no qual a criança seria capaz de argumentar precocemente - já aos dois anos -, aqueles baseados em teorias da argumentação linguística parecem demonstrar que a argumentação é um fenômeno adquirido tardiamente pelo indivíduo - mais ou menos aos dez anos de idade.

Leitão e Banks-Leite (2013, p.45) consideram que essas divergências são devidas às "concepções de argumentação em que se ancoram os estudos, da maneira como, implícita ou explicitamente, 
são definidas as relações entre as dimensões cognitiva e discursiva da argumentação, bem como de opções metodológicas adotadas na investigação empírica da argumentação infantil". No caso da abordagem filosófico-retórica, a coleta dos dados é predominantemente naturalística, já que são observadas situações naturais de fala eliciada, permitindo a análise da produção verbal oral das crianças na interação com um adulto (pais, professores ou pesquisador) ou na interação com outras crianças.

Um exemplo de pesquisa desse tipo foi conduzida por Ferreira (2005), na qual a pesquisadora observou situações de interação de crianças (de dois a quatro anos) com seus pais, no horário das refeições diárias. A partir da análise das produções verbais das crianças, a investigação permitiu concluir, segundo a autora, que elas podem antecipar posições contrárias aos seus argumentos dentro dos discursos, o que seria um indicativo da argumentação discursiva precoce. Pesquisas em uma perspectiva dialógica têm, igualmente, demonstrado um perfil precoce de aquisição da argumentação (CASTRO, 1992; DEL RÉ, 2003, 2013; VIEIRA; LEITÃO, 2014).

$\mathrm{Na}$ abordagem linguístico-discusiva, especialmente quando falamos de pesquisas baseadas na teoria da argumentação na língua, em muitos casos são criadas situações experimentais, nas quais as crianças devem refletir sobre a língua no que diz respeito aos elementos de argumentação. Neste tipo de pesquisa, são buscados indícios do nível de compreensão de tais elementos, por meio de situações controladas, tais como testes de entendimento, memorização, complemento de frases e juízos de aceitabilidade.

Neste artigo nos baseamos nas pesquisas que, em uma perspectiva psicolinguística, mostram que os elementos argumentativos que pressupõem o acesso a proposições implícitas, relacionadas a conhecimento de mundo ou a crenças, parecem ser compreendidos plenamente em etapa tardia quando considerada a aquisição da linguagem. Antes disso, as crianças conferem a estes elementos significados outros ou apenas os ignoram, retirando sentido dos demais itens presentes na oração, que ainda não é compreendida de modo analítico.

Kail e colaboradores (KAIL, 1978; 2013; KAIL; WEISSENBORN, 1984; 1991), a partir de diferentes testes, tais como de entendimento, memorização e juízo de aceitabilidade, concluíram que as crianças somente compreendem estes elementos por volta dos dez anos. Em torno dos seis anos, o elemento mas é interpretado como um coordenador, tal 
qual e. Quando a criança tem por volta de oito anos, ele é interpretado como um operador de implicação, com base na pragmática dos enunciados.

Kail e Weissenborn, em um estudo intitulado "A developmental cross-linguistic study of adversative connectives: French 'mais' and German 'aber/sodern'” (1984), contrastaram a aquisição do significado dos conectores adversativos por crianças francesas e alemãs (entre 7 anos e 8 meses a 9 anos e 11 meses), a fim de verificar, entre outras coisas, se o mas retificador ou, como as autoras nomeiam em inglês, substitutive but, seria mais facilmente processado e precocemente adquirido em comparação ao mas contrastivo ou argumentativo. Para tanto, foram realizados dois tipos de tarefas com base na oralidade: julgamento de gramaticalidade e complementação de sentenças. Os dois testes foram feitos a partir da escuta de textos lidos em voz alta pelo pesquisador. Como exemplo de texto oral utilizado nos dois testes - julgamento e complementação - temos: "In an indian village in Arizona there is a rodeo every year, where wild horses are tamed. The rodeo takes place in the centre of the village. Cowboys and Indians try to tame the horses and then there is a big picnic. The Indians are usually better at taming horses because they have been around horses since they were little children." (KAIL; WEISSENBORN, 1984, p.147).

O teste de complementação de sentenças com o mas contrastivo ou argumentativo foi constituído pelas seguintes sentenças, lidas pelo aplicador e complementadas oralmente pelos sujeitos: (1) "Joe is an Indian but he..."; (2) "Joe is not an Indian but he..."; (3) "Joe... but he won the rodeo."; (4) "Joe... but he did not win the rodeo."; (5) "Joe is a cowboy but he...".

Já o teste de julgamento para o mas contrastivo ou argumentativo foi constituído por sentenças, nas quais P levava a uma inferência baseada em um contexto, capazes de remontar e continuar uma história contada oralmente pelo pesquisador. $\mathrm{O}$ participante em teste deveria escolher a sentença que melhor remontasse ao contexto, a exemplo de: (1) "Joe is an Indian but he won the rodeo."; (2) "Joe is an Indian but he didn't win the rodeo."; (3) "Joe is not an Indian but he won the rodeo."; (4) "Joe is not an Indian but he didn't win the rodeo."; (5) "Joe is a cowboy but he won the rodeo."; (6) "Joe is a cowboy but he didn't win the rodeo.".

De acordo com as autoras, as hipóteses iniciais relativas à facilidade de processamento do mas retificador frente ao mas contrastivo e sua aquisição anterior são válidas, já que as crianças com mais idade 
têm um desempenho melhor nos testes de complementação e juízo de gramaticalidade em relação ao mas contrastivo ou argumentativo, enquanto em relação ao mas retificador o grupo de crianças mais novas teve igualmente um bom desempenho. Além disso, a partir das justificativas dadas para os julgamentos, as crianças mais novas demonstraram que o conector contrastivo é interpretado como um coordenador, como $e$, e a relação entre p e q é interpretada como uma implicação. Isso é demonstrado pela rejeição de sentenças, tais como "Joe is not an Indian but he won the rodeo", seguida da justificativa "If Joe is not an Indian then he cannot win". A mesma estratégia é usada na aceitação de sentenças agramaticais como "Joe is an Indian but he won the rodeo" (1984, p.154).

Resultado semelhante foi encontrado na pesquisa de Weirich (2016), realizada com dois grupos de estudantes adultos: um grupo (o experimental) considerado leitor, e outro grupo (o controle) considerado não leitor. $\mathrm{O}$ grupo de não leitores apresentou padrão de comportamento frente ao julgamento de gramaticalidade de enunciados complexos encadeados pelo mas argumentativo bastante semelhante ao comportamento das crianças mais jovens, o que parece ser um indicativo de que a devida compreensão do item linguístico que marca a argumentação no contexto frasal, neste caso o mas, ocorre somente quando há domínio do sistema de escrita. Além de terem desempenho significativamente inferior ao do grupo experimental, principalmente em termos de acurácia, os participantes do grupo controle fizeram comentários, como o exemplificado a seguir a partir das anotações do diário de campo da pesquisadora. Ao ouvir o enunciado "Rodrigo se arrependeu, mas voltou a cometer os mesmos erros", um participante do grupo controle disse: "Então ele não se arrependeu" e imediatamente clicou na tecla vermelha, julgando equivocadamente o enunciado como agramatical. ${ }^{8}$ Outro participante do grupo controle, ao ser exposto ao

\footnotetext{
${ }^{8}$ No estudo de Weirich (2016), por haver um grupo de sujeitos não leitores, estudantes de alfabetização em Educação de Jovens e Adultos, os participantes foram instruídos a julgar se o português estava bom. Para explicar o que significa bom português foi ministrada uma aula para cada participante, com exemplos semelhantes aos da coleta de dados. Não se falou em (a)gramaticalidade aos sujeitos para evitar uso de linguagem formal e especializada, o que poderia interferir nos resultados por (in)compreensão da tarefa proposta.
} 
enunciado oral "Rodrigo come carne gorda todos os dias, mas está acima do peso", prontamente se manifestou, dizendo: "Tem que estar mesmo", e optou pela gramaticalidade do enunciado (WEIRICH, 2016, p.88).

Bingham (1986) conduziu um estudo que trata do processamento de sentidos relacionais entre sentenças. A pesquisadora investigou as diferenças de processamento na compreensão leitora e oral de 90 sujeitos de 8, 11 e 14 anos, respectivamente no terceiro, sexto e nono anos de escolarização, os quais leram ou ouviram 40 pares de sentenças e escolheram conectores para completar a relação de sentido implícita. Exemplos de pares de sentenças usados no experimento (BINGHAM, 1986, p.54): 1. Relação causal (estímulo alvo): "They cut holes in the ice" e "They wanted to fish in the winter"; 2. Relação adversativa (estímulo alvo): "They can grow crops" e "There is no rain"; 3. Relação aditiva (distrator): "Jane is tal" e "She is a good reader"; 4. Relação temporal (distrator): "The fields were empty" e "Oil was discovered and reported".

Em cada par de sentenças, os sujeitos deveriam optar por um dos quatro conectores disponíveis: because (causal), although (adversativo), and (aditivo) e until (temporal). Os sujeitos, categorizados como tendo o nível adequado de leitura para a série escolar, foram divididos em dois grandes grupos. De um lado, aqueles que fizeram o teste por escrito e, de outro, os que fizeram o teste oralmente, somente a partir da escuta das instruções e das frases.

O estudo, segundo a autora, mostra que os grupos, de forma geral, tiveram desempenhos significativamente diferentes, tendo uma melhor performance nos testes de leitura do que nos testes de compreensão oral. Isso pode indicar, de acordo com a pesquisadora, que não há convergência entre compreensão leitora e compreensão oral. Ao mesmo tempo, a idade e a escolaridade foram variáveis significativas na compreensão das relações de sentido. No que se refere ao processamento das sentenças adversativas, os sujeitos de 8 anos tiveram um desempenho levemente melhor no teste de compreensão oral do que no teste de compreensão leitora, mas nos outros níveis os leitores tiveram um desempenho significativamente maior no entendimento da relação adversativa. A autora explica os dados a partir da ideia de que os leitores atentam mais para a estrutura superficial do que os ouvintes, podendo usar a estrutura 
superficial para estabelecer as relações de sentido no texto. Conforme cita Bingham (1986, p. 51, tradução nossa $\left.{ }^{9}\right)$ :

Goldman (1976) e Adams (1980) concluem que a compreensão do discurso linguístico escrito é diferente da compreensão do discurso linguístico oral, porque os leitores têm que observar as características da estrutura superficial da linguagem e os ouvintes não. Eles argumentam que os leitores devem usar a estrutura superficial da linguagem para estabelecer sentidos relacionais dentro do texto. Em contraste, os ouvintes podem depender da informação extralinguística disponível no contexto social da linguagem oral e nos sinais do falante. Se esta é uma descrição adequada de algumas das diferenças entre leitores e ouvintes, então, podemos esperar que os leitores sejam mais sensíveis a estruturas textuais explícitas, as quais estabelecem sentidos relacionais, do que os ouvintes.

Cain e Nash (2011), ao estudarem a influência dos conectivos no processamento e na compreensão de textos por leitores jovens, afirmam, com base em Kail e Weissenborn (1991), que crianças de 5 anos de idade são capazes de utilizar uma variedade de conectivos na oralidade. Entretanto, a aquisição destes elementos acontece em uma certa ordem, segundo a qual primeiro vêm os aditivos, como o $e$, seguidos dos conectivos temporais e causais. Apenas mais tardiamente aparecem os adversativos, categoria na qual o mas se inscreve. Tal característica da aquisição desses elementos parece sofrer interferência da aprendizagem e do domínio da leitura, já que os conectivos são dispositivos coesivos que assinalam as relações entre as frases e são fundamentais à construção de uma representação coerente do sentido do texto. Essa ordem de

\footnotetext{
${ }^{9}$ Excerto original: "Goldman (1976) and Adams (1980) conclude that comprehension of written language discourse is different from comprehension of oral language discourse because readers have to attend to surface structure characteristics of language and listeners do not. They argue that readers must use surface structures to establish relational meaning within the text. In contrast, listeners can depend on extra-linguistic information available from the social context of the oral language and the signals of the speaker. If this is a true description of some differences between readers and listeners, then, we could expect readers to be more sensitive to explicit text structures, which establish relational meaning, than listeners." (BINGHAM, 1986, p. 51).
} 
aquisição é, normalmente, atribuída à complexidade cognitiva de diferentes relações. As autoras esclarecem ainda que o uso apropriado dos conectivos, bem como o seu entendimento, continua em desenvolvimento por vários anos depois do aparecimento na produção. Elas acrescentam que até mesmo adultos podem ter dificuldades para apreciar as regras de foco mais sofisticadas associadas ao but e ao although. Tal dificuldade foi observada na pesquisa de Weirich (2016), conforme descrito acima.

Estudos realizados com crianças falantes de língua inglesa para testar o conhecimento, a compreensão e o processamento do elemento coesivo mas em períodos demonstram que crianças de 8 anos, embora possam fazer o uso adequado deste conectivo na oralidade, ainda apresentam dificuldades em exercícios do tipo cloze test (preenchimento de lacunas). A dificuldade diminui aos 10 anos de idade (CAIN; NASH, 2011). Isso pode ser explicado com base em Kail (2013) para quem a criança, aos 6 anos de idade, interpreta o mas como um operador de coordenação com valor de $e$. Portanto, enunciados como "Você brincou a tarde inteira na rua" e "está sujo e suado" são percebidos separadamente e, por isso, são aceitos quando encadeados pelo mas.

Com o intuito de investigar o uso da argumentação por crianças em idade escolar, Leitão e Almeida (2000) investigaram 157 crianças de segunda, quarta e sétima séries e sua capacidade de gerar contraargumentos na produção escrita. A pesquisa buscou verificar de que forma crianças e adolescentes, em diferentes etapas do processo tanto de aquisição de habilidades de raciocínio quanto de recursos linguísticos relativos à argumentação, lidam com o contra-argumento na sua produção escrita e como acontece a evolução no trato desse aspecto. Segundo as pesquisadoras, a condução da análise do uso de contra-argumentos levou em conta "qualquer ideia mencionada no curso de uma argumentação, que direta ou indiretamente enfraqueça o ponto de vista defendido pelo proponente de um argumento" (LEITÃO; ALMEIDA, 2000, p. 355). Embora os contra-argumentos sejam normalmente introduzidos por conectivos do tipo: embora, ainda que, mas, Leitão e Almeida não concentraram sua análise nos termos específicos, por julgarem não serem estes os únicos indicativos da presença da contra-argumentação na escrita das crianças e adolescentes participantes da pesquisa, uma vez que, segundo as autoras, as habilidades linguísticas desses escritores ainda está em desenvolvimento. Os resultados apontam para uma diferença entre as faixas etárias e os níveis escolares na frequência de uso de justificativas 
para seus pontos de vista e na antecipação de contra-argumentos para suas posições. Enquanto a antecipação de contra-argumentos nos textos escritos por crianças de $2^{\mathrm{a}}$ série (sete, oito anos) é apenas ocasional, na interpretação das pesquisadoras, passa a ser de uso sistemático na quarta série (dez, onze anos).

É relevante enfatizar que a perspectiva teórica assumida por estas pesquisadoras é discursiva e, mesmo assim, os resultados da pesquisa parecem respaldar a hipótese defendida no presente artigo, segundo a qual há interação entre os sistemas linguísticos verbais, no que diz respeito à interferência do conhecimento da linguagem verbal escrita para fins de leitura na maneira como se compreendem aspectos e elementos da argumentação linguística oral.

\section{Considerações finais: o domínio da leitura na compreensão oral da argumentação linguística}

Considerando a hipótese de Olson acerca da interação entre a escrita e a oralidade e acerca do papel que a escrita desempenha sobre a maneira como pensamos a linguagem, e considerando ainda as evidências, conforme apontam Kail e demais pesquisadores acima citados, de que os articuladores ou conectivos são adquiridos tardiamente e em fase na qual já houve apropriação do sistema de escrita pela via da leitura, levantamos a hipótese de que a aquisição tardia se justificaria pela exigência de uma condição específica de reflexão sobre a língua, que somente seria possível por meio do acesso significativo ao sistema escrita, como claramente evidenciam os dados da investigação de Weirich (2016). Tal condição permitiria a compreensão da função e dos valores de articuladores argumentativos, como é o caso do mas.

Assim, conforme apontam os estudos apresentados, o desempenho dos sujeitos na compreensão da linguagem pode indicar que a aprendizagem da leitura tem efeitos na análise e no entendimento de elementos argumentativos, já que estes apresentam sentidos relacionais específicos e contribuem para a construção do sentido do texto escrito. Enquanto na oralidade a compreensão depende, também, de informações disponíveis no contexto extralinguístico e nos sinais dados pelo locutor, na escrita, as informações são acessadas, unicamente, a partir da superfície textual, onde os elementos de argumentação estão linguisticamente representados. Desse modo, ao aprender a ler, o sujeito pode modificar 
sua compreensão da oralidade, sendo capaz de reconhecer a função argumentativa desses elementos.

No que diz respeito ao desenvolvimento da metalinguagem, mesmo que ele ocorra antes da aprendizagem da leitura e até desvinculado de um sistema de escrita, o envolvimento significativo dos sujeitos em contextos de uso da escrita para fins de leitura parece promover, segundo o que tem demonstrado a literatura, um tipo diferente de relação com a língua, propiciando que se crie um novo modelo de linguagem, respaldado na escrita, de modo que se possa, inclusive, a partir do erro, refletir sobre as diferenças de valores e funções dos elementos linguísticos de encadeamento argumentativo cuja compreensão envolva o acesso ao conteúdo implicitamente partilhado.

Citando o que propõe Olson (1997, p. 101), "as propriedades escritas proporcionam um modelo para a fala; aprender a ler é precisamente aprender esse modelo. Ironicamente, aprender a ler é aprender a ouvir o que é dito, de maneira diferente!”

\section{Referências}

ABREU, M. (Org.). Leitura, história e história da leitura. 3.ed. Campinas: Mercado de Letras/ALB/FAPESP, 2000. PMCid:PMC89876.

ANSCOMBRE, J. C.; DUCROT, O. Deux mais en français? Lingua, $v$. 43, p. 23-40, 1977.

BINGHAM, A.B. Readers' and listeners' use of cohesive ties in processing relational meaning. Language Sciences, v. 8, n.1, 1986, p. 49-61. https://doi.org/10.1016/S0388-0001(86)80005-5.

BLACHMAN, B. A. Phonological awareness. In: KAMIL, M. L.; MOSENTHAL, P. B.; PEARSON, P. D.; BARR, R. Handbook of reading research: volume III. New Jersey/London: Lawrence Earlbaum Associates, 2000. p.483-502.

BRITTO, L. P. L. Inquietudes e desacordos: a leitura além do óbvio. Campinas: Mercado de Letras, 2012.

CAGLIARI, L. C. Alfabetizando sem o bá-bé-bi-bó-bu. São Paulo: Scipione, 1998. 
CAIN, K.; NASH, H. M. The influence of connectives on young readers' processing and comprehension of text. Journal of Educational Psychology, v. 103, n.2, p. 429-441, maio 2011. https://doi.org/10.1037/ a0022824.

CAREL, M. Pourtant: argumentation by exception. Journal of Pragmatics, v. 24, p.167-188, 1995. https://doi.org/10.1016/0378-2166(94)00106-O.

CASTRO, S.L. A linguagem escrita e o seu uso: uma perspectiva cognitiva. In: GRIMM-CABRAL, L.; MORAIS, J. (Org.). Investigando a linguagem. Florianópolis: Mulheres, 1999.

CASTRO, M.F.P. de. Aprendendo a argumentar. Campinas: Editora da Unicamp, 1992.

CHARTIER, R. Práticas de leitura. Tradução de Cristiane Nascimento. São Paulo: Estação Liberdade, 1996.

CHARTIER, R. Os desafios da escrita. Tradução de Fulvia M. L. Moretto. São Paulo: Unesp, 2002.

DEL RÉ, A. A pesquisa em aquisição da linguagem: teoria e prática. In: DEL RÉ, A. et al. Aquisição da linguagem: uma abordagem psicolinguística. 2 ed. São Paulo: Contexto, 2013. p. 13-44.

DEL RÉ, A. A criança e a magia da linguagem: um estudo sobre o discurso humorístico. São Paulo, 2003. Tese (Doutorado em Linguística) - Faculdade de Filosofia, Letras e Ciências Humanas, Universidade de São Paulo, 2003.

DUCROT, O. O dizer e o dito. Revisão técnica da tradução de Eduardo Guimarães. Campinas: Pontes, 1987. PMid:3442742.

DUCROT, O. Argumentação e "topoi” argumentativos. In: GUIMARÃES, E. (Org). História e sentido da linguagem. Campinas: Pontes, 1989. p.13-38.

DUCROT, O. Os internalizadores. Letras de Hoje. Porto Alegre, v. 37 , n.3, p. 7-26, set. 2002.

DUCROT, O. Argumentação retórica e argumentação linguística. Letras de Hoje, Porto Alegre, v. 44, n. 1, p. 20-25, 2009.

DUCROT, O.; CAREL, M. Descrição argumentativa e descrição polifônica: o caso da negação. Letras de Hoje, Porto Alegre, v. 43, n. 1, p. 7-18, 2008. 
EHRI, L. C. O desenvolvimento da leitura imediata de palavras: fases e estudos. In: SNOWLING, M. J.; HULME, C. (Org.). A ciência da leitura. Tradução de Ronaldo Cataldo Costa. Porto Alegre: Penso, 2013. p. 153-172.

FARACO, C.A. Linguagem escrita e alfabetização. São Paulo: Contexto, 2012.

FERREIRA, A. P. M. O desenvolvimento de condutas opositivas em crianças: antecipação de posições contrárias. 2005. Dissertação (Mestrado) - Programa de Pós-graduação Psicologia Cognitiva, Universidade Federal de Pernambuco, Recife. 2005.

FROST, R. Sistemas ortográficos e processos de reconhecimento de palavras na leitura. In: SNOWLING, M. J.; HULME, C. (Org.). A ciência da leitura. Tradução de Ronaldo Cataldo Costa. Porto Alegre: Penso, 2013. p. 290-313.

GIL, A. C. Como elaborar projetos de pesquisa. 5. ed. São Paulo: Atlas, 2010.

GODOY, D. M. A. Aprendizagem inicial da leitura e da escrita no português do Brasil: Influência da consciência fonológica e do método de alfabetização. 2005. Tese (Doutorado) - Programa de Pós-graduação em Linguística, Universidade Federal de Santa Catarina, Florianópolis. 2005.

GRAY, D. E. Pesquisa no mundo real. 2. ed. Porto Alegre: Penso, 2012. KAIL, M. La compréhension des présuppositions chez I'enfant. L'Anée psychologique, 78, p. 425-444, 1978.

KAIL, M. Aquisição de linguagem. Tradução de Marcos Marcionilo. São Paulo: Parábola, 2013.

KAIL, M.; WEISSENBORN, J. A developmental crosslinguistic study of adversative connectives: French "mais" and German "aber/sodern". Journal of Child Language, 11, p. 143-158, 1984. https://doi.org/10.1017/ S0305000900005638. PMid:6699107.

KAIL, M.; WEISSENBORN, J. Conjunctions: Developmental Issues. In: PIÉRAUT-LE-BONNIEC, G.; DOLITSKY, M. (Org.). Language Bases: Discourse Bases. Amsterdam: Benjamins, 1991. 
KAMIL, M. L.; MOSENTHAL, P. B.; PEARSON, P. D.; BARR, R. Handbook of Reading Research: volume III. New Jersey/London: Lawrence Earlbaum Associates, 2000.

LEITÃO, S.; ALMEIDA, E. G. S. A Produção de Contra-Argumentos na Escrita Infantil. Psicologia: Reflexão e Crítica, v. 13, n. 3, p.351-361, 2000. https://doi.org/10.1590/S0102-79722000000300004.

LEITÃO, S.; BANKS-LEITE, L. Argumentação na linguagem infantil: algumas abordagens: In: DEL RÉ, A. (Org.). Aquisição da linguagem: uma abordagem psicolinguística. 2.ed. São Paulo: Contexto, 2013. p. 45-61.

LEMOS, C.T.G. Das vicissitudes da fala da criança e de sua investigação. Caderno de Estudos Linguísticos. Campinas, v. 42, p. 41-69, 2002.

LEYBAERT, J. Aprendendo a ler com uma deficiência auditiva. In: SNOWLING, M. J.; HULME, C. (Org.). A ciência da leitura. Tradução de Ronaldo Cataldo Costa. Porto Alegre: Penso, 2013. p. 397-414.

McGUINNESS, D. Why our children can't read and what we can do about it: a scientific revolution in Reading. New York: Touchstone, 1999. PMCid:PMC1905163.

McGUINNESS, D. $O$ ensino da leitura: o que a ciência nos diz sobre como ensinar a ler. Tradução de Luzia Araújo. Porto Alegre: Artmed, 2006.

MORAIS, A. G. de. (Org.). O aprendizado da ortografia. 4. ed. Belo Horizonte: Autêntica, 2011.

MORAIS, A. G. de. Sistema de escrita alfabética. São Paulo: Melhoramentos, 2012.

MORAIS, J. Alfabetizar para a democracia. Porto Alegre: Penso, 2014.

MORAIS, J.; KOLINSKY, R. Letramento e mudança cognitiva. In: SNOWLING, M. J.; HULME, C. (Org.). A ciência da leitura. Tradução de Ronaldo Cataldo Costa. Porto Alegre: Penso, 2013. p. 207-222.

MOURA, H. M. M. Semântica e argumentação: diálogo com Oswald Ducrot. D.E.L.T.A: Documentação de Estudos em Linguística Teórica e Aplicada, v. 14, n. 1, p.1-7, fev. 1998. https://doi.org/10.1590/S010244501998000100008 . 
OLSON, D. R. From utterance to text: the bias of language in speech and writing. Harvard Educational Review, 47, p. 257-281, 1977. https://doi. org/10.17763/haer.47.3.8840364413869005.

OLSON, D. R. Towards a psychology of literacy: on the relations between speech and writing. Cognition, [s.i], v. 60, p.83-104, 1996.

OLSON, D. R. O mundo no papel: as implicações conceituais e cognitivas da leitura e da escrita. São Paulo, Ática: 1997.

OLSON, D. R.; OATLEY, K.. The Quotation Theory of Writing. Written Communication, [s.1.], v. 31, n. 1, p.4-26, dez. 2014.

ORDEN, G. C. V.; KLOOS, H. A relação entre fonologia e leitura. In: SNOWLING, M. J.; HULME, C. (Org.). A ciência da leitura. Tradução de Ronaldo Cataldo Costa. Porto Alegre: Penso, 2013. p. 79-96.

SALLES, J. F.; PARENTE, M. A. M. P. Relação entre os processos cognitivos envolvidos na leitura de palavras e as habilidades de consciência fonológica em escolares. Pró-Fono Revista de Atualização Científica. Carapicuíba, SP, v. 14, n. 2, p. 175-186, maio-ago. 2002.

SCLIAR-CABRAL, L. Princípios do sistema alfabético do português do Brasil. São Paulo: Contexto, 2003.

SCLIAR-CABRAL, L. Sistema Scliar de alfabetização: fundamentos. Florianópolis: Lili, 2013.

SEIMETZ-RODRIGUES, C.; SOUZA, A. C. Ensino da leitura a surdos: o conhecimento do objeto de ensino e suas implicações para a prática pedagógica. Revista Linguagem e Ensino, Pelotas, RS, v. 19, n.1, p.55-79, jan.-jun. 2016.

SOUZA, A. C. Leitura emergente: a alfabetização como chave à produção de sentidos a partir do escrito. In: GARCIA, W. A. C; SOUZA, A. C. A produção de sentidos e o leitor: os caminhos da memória. Florianópolis: NUP/CED. 2012. p. 43-60. PMid:22441595.

VASCONCELOS, E. M. Complexidade e pesquisa interdisciplinar: epistemologia e metodologia operativa. 6. ed. Petrópolis, RJ: Vozes, 2013. VIEIRA, A.J.; LEITÃO, S. Argumentação e explicação. In: DEL RÉ, A.; PAULA, L.; MENDONÇA, M.C. (Org.). Explorando o discurso da criança. São Paulo: Contexto, 2014. 
VOGT, C. O intervalo semântico - contribuição para uma teoria semântica argumentativa. 1974. Tese (Doutorado) - Programa de Pós-graduação em Linguística, Universidade Estadual de Campinas, Campinas, 1974.

WEIRICH, H. C. Domínio da leitura e compreensão oral do mas argumentativo. 2016. Dissertação (Mestrado) - Programa de Pósgraduação em Linguística, Universidade Federal de Santa Catarina, Florianópolis. 2016.

WELP, A.K.S. Uma visão argumentativa do mas. Letras de Hoje, Porto Alegre, v. 40, n. 1, p. 299-325, mar. 2005. 